null • Business of Knowing, summer 2021

\title{
Trust in Infrastructure
}

\section{Colleen Cressman}

Published on: Aug 20, 2021

DOI: $10.21428 / 6 \mathrm{ffd} 8432 . a e 158 f 91$

License: Creative Commons Attribution 4.0 International License (CC-BY 4.0). 


\section{ABSTRACT}

We commonly think of infrastructure as purpose-built tools that enable us to carry out activities and tasks that are typically critically important. In scholarly publishing, these tools are important to us as authors, readers, and practitioners who seek to access and communicate knowledge. In this article, I claim that infrastructure is an activity. It's not until we press a button, enter a query, or engage it in some way that it can serve the functions it's built to carry out. In other words, we need to interact with infrastructure in order to make it go. And once we do that, we don't question whether it will work. In fact, we rely on infrastructure to such an extent that when it fails, we feel betrayed. Infrastructure, then, is an activity that involves our use of tools and engenders our trust. This conception of infrastructure lets us see why it matters so much. Infrastructure is tied to who we are, and our engagement with it impacts who we can become.

\section{Infrastructure as Tool We Rely On}

We commonly think of infrastructure as objects, services, software, and networks-as purpose-built tools that enable us to carry out activities and tasks that are typically critically important. $\underline{1}$ In scholarly publishing, these tools are important to us as authors, readers, and practitioners who seek to access and communicate knowledge. Consider the following definitions:

We define infrastructure as the systems, protocols, and software that research and scholarship rely on. Open infrastructure...[is] the narrower set of open source solutions that facilitate the creation and dissemination of open content, and empower communities to deliver new, improved collective benefits without restrictions to participation, engagement, or usage. (Invest in Open Infrastructure 2021).

Open science infrastructures refer to shared research infrastructures-including major scientific equipment or sets of instruments, $[,,$,$] collections, repositories,$ archives and scientific data, open computational infrastructures that enable data analysis and digital infrastructures-that are needed to support Open Science and serve the needs of different communities. (UNESCO 2021, $\underline{5}$ ). 
[Infrastructures are] organisations that provide support services to the OA diamond journals to perform certain technical tasks, such as copy-editing, dissemination, hosting, indexation, preservation, registration or typesetting. (스 Diamond Journals Study 2021, 12).

These definitions differ in scope and content, and target distinct but overlapping communities, including those that may use the infrastructure and those that may be served by it. For my purposes, I will focus on features they have in common. First, infrastructure is functionally defined. We use it as a tool to carry out important tasks, and insofar as we are able to read, publish, discover, communicate, and so on, it has done the job it was built to do. In this way, infrastructure becomes what it is in relation to the activities it supports or makes possible to perform. Just as a tool "emerges in situ," so infrastructure "emerges for people in practice, connected to activities and structures." Hence, it's not a question of what infrastructure is, but when. $\underline{2}$. Star and

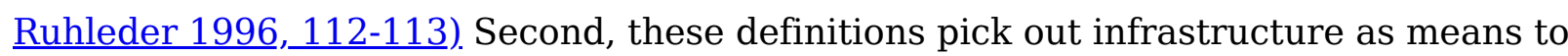
our ends. Ethan Zuckerman (2020). puts it simply, "Infrastructures are things we build so we can build other things." Third, we rely on it. Infrastructure is necessary. Without it, we wouldn't be able to get things done. Taking these features together, we see that protocols, repositories, indexes, and services that underlie production activities, like typesetting, may all serve as pieces of infrastructure according to these definitions.

In this article, I propose a conception of infrastructure that goes beyond its functioning as a necessary tool in our kit. I claim that infrastructure is (1) an activity that involves (2) an agent and (3) her trust in (4) the tools she uses. This conception of infrastructure lets us see why it matters so much. Infrastructure is tied to who we are, and our engagement with it impacts who we can become.

\section{Infrastructure as Activity We Do}

Infrastructure figures into our activities. Since it may be conceived as a tool-even if that's not all it is-we agents are involved in its operation and, even, in determining what (or when) infrastructure is. I propose we think of infrastructure as an activity we do. $\underline{3}$ That activity involves our use of tools and, as I will later argue, our trust. Accordingly, I place more emphasis on the individual, the agent herself, in contrast to Susan Star and Karen Ruhleder (1996). In this framing, I follow Christine Korsgaard (2009), who analyzes artifacts as activities. I take this analysis to have implications for infrastructure, insofar as infrastructure is conceived as a species of artifacts. What Korsgaard correctly observes about artifacts should inform our conception of infrastructure. 
Recall that infrastructure is often functionally defined the way a tool is. According to Korsgaard, artifacts tend to need some sort of intervention in order to operate.

[Most artifacts] need either a power source, or to be wielded by a human being, or both, before they can perform their functions. It isn't quite right, then, to say of the vacuum cleaner in your closet that it "can clean floors," since, actually, until you plug it in and wield it, it cannot. So strictly speaking, artifacts, when they are just sitting around doing nothing..., are incomplete objects that will only start to perform their function when some last part is plugged in or inserted. (36-37, emphasis omitted)

Korsgaard's incomplete object, or the entity that has yet to be taken up in use as an artifact, is similar to Star and Ruhleder's notion that infrastructure emerges in practice. This seems right. An author queries the Directory of Open Access Journals (DOAJ) for a potential no-fee publishing venue, a cataloger adds metadata to a record to enable discovery, a student attaches a Creative Commons license to the class project she's uploading to her institutional repository, and so on. These are all tasks familiar to us in scholarly publishing, broadly construed. And it's not until the agent engages them in some way that such entities can serve the functions they're built to carry out. In order for DOAJ, metadata records, Creative Commons licenses, and institutional repositories to be pieces of infrastructure at all, they require an agent to act.

But Korsgaard's account of artifacts-and what I am saying about infrastructure-is more specific. It places the agent at center, for she "incorporates" the object into her agency. This is the mechanism by which an otherwise incomplete object becomes an artifact.

[T]here is no such artifact as a vacuum cleaner at all. Instead, what you call your vacuum cleaner is actually an entity that, when properly incorporated by you, makes you into a vacuum cleaner. (프, emphasis original).

Just so with infrastructure. We identify the repository as the infrastructure, rather than ourselves and the entire causal chain that led to the availability of our research outputs, because the repository is easy to pick out as the site of action. Korsgaard makes this point of artifacts: she says we pick out a knife as the cause of cutting "because we can use the knife for cutting." (느, emphasis original). This partially explains why our necessary role in the functioning of infrastructure as infrastructure seems to fade into the background. By conceiving of infrastructure as an activity we 
do, however, we are less likely to overlook our involvement than if we think of infrastructure more simply as a tool.

Why bother with this conception? It is our ability to engage the tools that enables us to write, read, create and share knowledge-to carry out the tasks that are important to us and to others who depend on their completion. $\underline{4}$ And crucially, whether and to what extent we can use them, these tools play a role in determining who can become authors, readers, and practitioners in the first place. $\underline{5}$ If we think of infrastructure as an activity we do, then we can see more clearly who is included in it, and importantly, who is excluded from it.

\section{Trust in Infrastructure}

So far, infrastructure is an activity that involves the agent and her use of tools. There is one more feature to add. We need to distinguish infrastructure from tools more generally. We rely on infrastructure, just as we rely on tools. But there is something more to it. Infrastructure denotes the tools-and as I argue, activities-that are of central importance to our own functioning. We rely on infrastructure to such an extent that when it fails, we feel betrayed. In short, we pick out infrastructure as such when these tools engender our trust, not merely our reliance on them.

It may seem unintelligible to say that we trust our tools at all, that we instead reserve trust for other people-our friends, family, colleagues, and perhaps the makers of those tools. C. Thi Nguyen (forthcoming), however, argues trust can extend to agents and objects alike when when construed as an 'unquestioning attitude.' According to Nguyen, "To trust something...is to put its reliability outside the space of evaluation and deliberation." (2). When we trust, we have "stepped back from the deliberative process." (므) Simply, we adopt a disposition of not questioning the tools we use and whether they will operate as needed to carry out our tasks. (10). This is the unquestioning attitude, and Nguyen says, we can't trust without it. (23). So, we can trust our tools, especially those that are necessary for our success as authors, readers, and practitioners. And when we do, I claim, our tools serve as infrastructure.

Consider trust in the context of scholarly publishing. Journals that use repositories to carry submissions through to acceptance, and publish the final outputs back onto the repository for hosting, are relying on the repository as a necessary means of engaging in a range of publishing activities. This is how Discrete Analysis, Advances in Combinatorics, and Ars Inveniendi Analytica operate using the open repository, arXiv. It's often remarked that setting up journals this way reduces costs, and the journals 
are therefore better equipped to remain free of reader- and authorside fees. $\underline{6}$ But another reason to find this model valuable is its engendering of trust. By making use of established, open tools that mathematicians are already deeply familiar using, these journal are "lower[ing] the barrier of monitoring, challenging, checking, and questioning" among authors, readers, reviewers, and editorial teams alike. $\underline{7}$ (Ng $\underline{\text { uyen }}$, $\underline{5}$ ). These individuals don't simply rely on arXiv to host and deliver research; they trust that it does. How so? They don't question that arXiv will continue to operate in the manner they have come to expect and depend on, and in the case of the journals above, even that arXiv is playing a central role throughout the editorial process. In other words, they engage arXiv to carry out tasks of vital importance to their own ends as agents without monitoring, challenging, and checking that the repository will come through for their purposes.

When we engage infrastructure as infrastructure, we take up these tools into our own functioning as an activity we do-with one last addition: we adopt the unquestioning attitude; that is, we trust. According to Nguyen, trust as an unquestioning attitude is

to let something inside, to let it play an immediate role in one's cognition and activity....Trust is our mechanism for integrating other people and objects into our own functioning. (므, emphasis original).

When we trust a tool as infrastructure, we are disposed not to question whether it will work. And if our tools do break down or become unavailable, we aren't just disappointed; we feel betrayed. Consider the acquisition of a tool by one company or entity from another, an all-too familiar phenomenon in scholarly publishing. This is one way a tool may become unavailable to us and erode our trust. $\underline{8}$ Following acquisition, a tool may become cost prohibitive, features may be curtailed, or it may shut down altogether. We may continue to depend on such tools, as we may rely on them due to lack of ready alternatives or because their embeddedness in our workflows make them difficult or impossible to extricate. But we no longer trust them, and our attitude shifts from one that doesn't question their continued performance, toward one of suspicion or uncertainty, perhaps even accompanied by a feeling of betrayal. $\underline{9}$

In fact, the sting of betrayal indicates that we had trusted, and we feel it most strongly toward "[t]he external objects...whose functions are most tightly integrated into our own thinking and functioning." (Nguyen, 26-27). In scholarly publishing, these are the tools that are critical to our ability to be and become authors, readers, and practitioners. It is no wonder why we are seeking out ways to ensure our tools' durability, resist their enclosure, and to enhance their availability among individuals 
and groups who are too often excluded from participating in the creation and sharing of knowledge.

To conclude as we began, with a definition: infrastructure is (1) an activity that involves (2) an agent and (3) her trust in (4) the tools she uses. This conception lets us readily see how fundamental infrastructure is, and it underscores the importance of the work that Invest in Open Infrastructure, UNESCO, and no-fee open access publishers are undertaking in order to develop and maintain the tools that enable us to realize our ends and engender our trust.

\section{$\square$ read more essays in the "Business of knowing" summer series $\square$}

\section{Footnotes}

1. I am grateful to Mitch Nakaue and Ian Dunkle for their generous input and encouragement as I developed this article, as well as to Catherine Ahearn and Sarah Kearns for their insightful comments and editorial expertise. I would also like to acknowledge the scholarship of Christine Korsgaard and Thi Nguyen, which is foundational for the view of infrastructure I present and continues to be a source of inspiration. $\_$

2. 
Star and Ruhleder go on to stipulate several dimensions of infrastructure, and maintain that it resists "absolute boundary," (113) following Star and Griesemer's earlier (1989) analysis of 'boundary objects.'

Star, Susan Leigh and James R. Griesemer. 1989. "Institutional Ecology, 'Translations' and Boundary Objects: Amateurs and Professionals in Berkeley's Museum of Vertebrate Zoology, 1907-39." Social Studies of Science 19(3): 387-420. https://doi.org/10.1177/030631289019003001

For a conception of open access as a boundary object, see:

Moore, Samuel A. 2017. “A Genealogy of Open Access: Negotiations between Openness and Access to Research." Revue française des sciences de l'information et de la communication. https://doi.org/10.4000/rfsic.3220

3. Star and Ruhleder (1996) hold that infrastructure is a relation between agent and tool, and is not an object (or property of an object) to be analyzed independently. Their view of infrastructure has several dimensions. When I refer to infrastructure as an activity, I am not coming down on whether that also makes it a relation. $\subseteq$ 4. The workers who perform critical labor to keep these systems running are also incorporating their agency into the process. I have not used the term 'end user' in this article precisely for this reason. Anyone who engages a system, object, network (and so forth) can be participating in the activity of infrastructure. What may be different is the field of view: what more immediately supports a cataloger's tasks differs from that which supports a researcher's retrieval of a record. (For interesting work in the area of infrastructural maintenance, see The Maintainers:

\section{https://themaintainers.org $L) \subseteq$} 5.

See Jonathan Gray (2020). on what the author calls 'infrastructural experiments,' which "may serve to facilitate collective inquiry into who and what research is for, as well as 'infrastructural imagination' about how it may be organized differently." (253) Gray organizes the chapter around the following questions: Who has access? What counts? What matters? And, how are relations reconfigured?

Gray, Jonathan. 2020. "Infrastructural Experiments and the Politics of Open Access." In Reassembling Scholarly Communications: Histories, Infrastructures, and Global Politics of Open Access, eds. Martin Paul Eve and Jonathan Gray. MIT Press. https://doi.org/10.7551/mitpress/11885.001.0001 
6. See Ars Inveniendi Analytica on cost-savings, e.g.: "This particular publishing model minimizes the operating costs of a journal...to such a low level that full support is possible within the budget of a single sponsoring library....As a result, publishing a paper on the journal is entirely free for authors." $\triangleq$

7. Nguyen is describing the general phenomenon of trust; I am applying it to arXiv and the journals that use it for publishing activities. $\_$

8. I thank Catherine Ahearn for this explicit connection. $\bullet$

9. Nguyen (forthcoming) makes this point regarding the loss of trust in cases where individuals, following earthquakes, must continue to rely on the ground, even without trusting it. (12) $匚$

\section{Citations}

1. Invest in Open Infrastructure. 2021. "Strategic Plan for 2021-2024." https://investinopen.org/about/strategic-plan-2021-2024/

2. UNESCO. 2021. "Draft Text of the UNESCO Recommendation on Open Science." https://unesdoc.unesco.org/ark:/48223/pf0000376893.locale=en

3. Bosman, Jeroen, Jan Erik Frantsvåg, Bianca Kramer, Pierre-Carl Langlais, Vanessa Proudman. 2021. "The OA Diamond Journals Study, Part 1: Findings." http://doi.org/10.5281/zenodo.4558704

4. Star, Susan Leigh and Karen Ruhleder. 1996. "Steps Toward an Ecology of Infrastructure: Design and Access for Large Information Spaces." Information Systems Research 7(1): 111-134. https://www.jstor.org/stable/23010792 5. Zuckerman, Ethan. 2020. “What Is Digital Public Infrastructure?” Center for Journalism \& Liberty. https://www.journalismliberty.org/publications/what-is-digitalpublic-infrastructure $\doteq$

6. Star, Susan Leigh and Karen Ruhleder. 1996. "Steps Toward an Ecology of Infrastructure: Design and Access for Large Information Spaces." Information Systems Research 7(1): 111-134. https://www.jstor.org/stable/23010792 7. Korsgaard, Christine. 2009. "The Metaphysics of Normativity." In SelfConstitution: Agency, Identity, and Integrity. Oxford University Press. 
https://oxford.universitypressscholarship.com/view/10.1093/acprof:oso/97801995527 95.001.0001/acprof-9780199552795

8. Korsgaard, Christine. 2009. "The Metaphysics of Normativity." In SelfConstitution: Agency, Identity, and Integrity. Oxford University Press. https://oxford.universitypressscholarship.com/view/10.1093/acprof:oso/97801995527 $\underline{95.001 .0001 / a c p r o f-9780199552795}$

9. Korsgaard, Christine. 2009. "The Metaphysics of Normativity." In SelfConstitution: Agency, Identity, and Integrity. Oxford University Press. https://oxford.universitypressscholarship.com/view/10.1093/acprof:oso/97801995527 $\underline{95.001 .0001 / a c p r o f-9780199552795}$

10. Korsgaard, Christine. 2009. "The Metaphysics of Normativity." In SelfConstitution: Agency, Identity, and Integrity. Oxford University Press. https://oxford.universitypressscholarship.com/view/10.1093/acprof:oso/97801995527

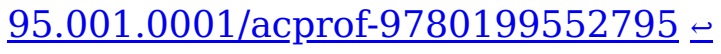

11. Nguyen, C. Thi. Forthcoming. "Trust as an unquestioning attitude." In Oxford Studies in Epistemology. Oxford University Press. Manuscript. https://philpapers.org/rec/NGUTAA $\leftrightharpoons$ 12. Nguyen, C. Thi. Forthcoming. "Trust as an unquestioning attitude." In Oxford Studies in Epistemology. Oxford University Press. Manuscript. https://philpapers.org/rec/NGUTAA $\leftrightharpoons$ 13. Nguyen, C. Thi. Forthcoming. "Trust as an unquestioning attitude." In Oxford Studies in Epistemology. Oxford University Press. Manuscript. https://philpapers.org/rec/NGUTAA

14. Nguyen, C. Thi. Forthcoming. "Trust as an unquestioning attitude." In Oxford Studies in Epistemology. Oxford University Press. Manuscript. https://philpapers.org/rec/NGUTAA $\leftrightharpoons$ 15. Nguyen, C. Thi. Forthcoming. "Trust as an unquestioning attitude." In Oxford Studies in Epistemology. Oxford University Press. Manuscript. https://philpapers.org/rec/NGUTAA $\triangleq$

16. Ars Inveniendi Analytica. "For Authors." https://ars-inveniendi-analytica.com/forauthors $\triangleq$ 
17. Nguyen, C. Thi. Forthcoming. "Trust as an unquestioning attitude." In Oxford Studies in Epistemology. Oxford University Press. Manuscript. https://philpapers.org/rec/NGUTAA $\leftrightharpoons$

18. Nguyen, C. Thi. Forthcoming. "Trust as an unquestioning attitude." In Oxford Studies in Epistemology. Oxford University Press. Manuscript. https://philpapers.org/rec/NGUTAA $ヒ$

19. Nguyen, C. Thi. Forthcoming. "Trust as an unquestioning attitude." In Oxford Studies in Epistemology. Oxford University Press. Manuscript. https://philpapers.org/rec/NGUTAA $\subseteq$ 